\title{
Social inequalities in depressive symptoms and physical functioning in the Whitehall II study: exploring a common cause explanation
}

\author{
S A Stansfeld, J Head, R Fuhrer, J Wardle, V Cattell
}

See end of article for authors' affiliations

Correspondence to Professor S A Stansfeld, Department of Psychiatry, Medical Sciences Building, Mile End Road, London El 4NS, UK:

S.A.Stansfeld@qmul.ac.uk

Accepted for publication 26 September 2002

\begin{abstract}
Study objective: This study investigated which risk factors might explain social inequalities in both depressive symptoms and physical functioning and whether a common set of risk factors might account for the association between depressive symptoms and physical functioning.

Design: A longitudinal prospective occupational cohort study of female and male civil servants relating risk factors at baseline (phase 1: 1985-8) to employment grade gradients in depressive symptoms and physical functioning at follow up (phase 5: 1997-9). Analyses include the 7270 men and women who participated at phase 5 .

Setting: Whitehall II Study: 20 London based white collar civil service departments. Participants: Male and female civil servants, 35-55 years at baseline.

Main results: Depressive symptoms were measured by a subscale of items from the 30 item General Health Questionnaire. Physical functioning was measured by a subscale of the SF-36. Employment grade was used as a measure of socioeconomic position as it reflects both income and status. The grade gradient in depressive symptoms was entirely explained by risk factors including work characteristics, material disadvantage, social supports, and health behaviours. These risk factors only partially explained the gradient in physical functioning. The correlation between depressive symptoms and physical functioning was reduced by adjustment for risk factors and baseline health status but not much of the association was explained by adjustment for risk factors. Among women, the association between depression and physical functioning was significantly stronger in the lower grades both before and after adjustment for risk factors and baseline health. For women, there was only a significant grade gradient in depressive symptoms among those reporting physical ill health.

Conclusions: Some risk factors contribute jointly to the explanation of social inequalities in mental and physical health although their relative importance differs. Work is most important for inequalities in depressive symptoms in men, and work and material disadvantage are equally important in explaining inequalities in depressive symptoms in women while health behaviours are more important for explaining inequalities in physical functioning. These risk factors did not account for the association between mental health and physical health or the greater comorbidity seen in women of lower socioeconomic status. The risk of secondary psychological distress among those with physical ill health is greater in the low employment grades.
\end{abstract}

M any studies have shown gradients in physical ill health and mortality by socioeconomic position. ${ }^{1-7}$ Social gradients have also been found for major mental illness ${ }^{89}$ and for common mental disorder including depression. ${ }^{10-12}$ Explanations for these gradients have included work characteristics, ${ }^{13}$ adverse exposures in childhood,$^{14}{ }^{15}$ life events and material resources. ${ }^{12}$

The question arises, if there is a similar gradient in both physical and psychological morbidity, could there be explanations of the gradient that influence both physical and psychological health? As psychological and physical ill health are linked, ${ }^{1617}$ one explanation might be that psychological ill health is a risk factor for physical illness (psychosomatic explanation). Another explanation might be that common mental disorder is a consequence of the pain, threat to life, and disability associated with physical illness. A further possibility is that certain risk factors influence both psychological and physical health, the so called common cause hypothesis. ${ }^{18}$ Such an explanation would have important policy relevance as it would suggest that interventions could be targeted to reduce inequalities in both psychological ill health and physical illness simultaneously. This paper explores the gradient in physical functioning and depressive symptoms in the prospective Whitehall II study of male and female civil servants. It examines the association of depressive symptoms and physical functioning by employment grade and determines whether this can be explained by a common set of risk factors.

\section{METHOD}

\section{Study population}

The Whitehall II study was set up to investigate the degree and causes of the social gradient in morbidity and mortality and to include work characteristics and social support as potential factors related to the gradient in mortality. ${ }^{2}$ A cohort of civil servants was established between 1985 and 1988 (phase 1). All male and female civil servants, aged between 35 and 55 years, in 20 London based civil service departments were sent an introductory letter and screening questionnaire and had a screening examination including measurement of blood pressure, an electrocardiogram, and a blood sample. Altogether 10308 civil servants were examined-6895 men (67\%) and 3413 women $(33 \%)$. After the initial participation at phase 1 , a further postal questionnaire was carried out in 1989 (phase 2 ) and the participants were approached again for a further screening examination in 1991/93 (phase 3: questionnaire and screening examination). A further postal questionnaire was carried in 1995-6 (phase 4) and a further clinical examination 
and questionnaire in 1997-9 (phase 5). The participation rates at phases 3 and 5 were $83 \%$ and $76 \%$ respectively. Full details of the screening examinations are reported elsewhere. ${ }^{2}$

\section{Grade of employment}

The civil service identifies 12 non-industrial grades on the basis of salary that have been grouped into six categories. There was a steep increment in salaries from an annual salary in 1987 of between $£ 3061$ to $£ 5841$ in the clerical and office support grades to between $£ 18020$ to $£ 62100$ in the topmost grades (Unified 1-6). By 1995 the differential in salaries between the clerical and office support grades on $£ 4995$ to $£ 10999$ and the topmost grades on $£ 28975$ to $£ 150000$ had increased. Besides the steep differential in salaries there were also marked differences in other socioeconomic indicators (education, housing tenure, car ownership, and father's occupation) by grade of employment. ${ }^{2}$

\section{Instruments}

\section{Depressive symptoms}

A four item depression subscale scored 0-12 (Cronbach's $\alpha=0.88$ ) was identified from the 30 item General Health Questionnaire ${ }^{19}$ on the basis of factor analysis and comparison with the items of the depression subscale of the 28 item General Health Questionnaire. ${ }^{20}$ At phase 3, a subsample of 286 participants repeated the questionnaire one month later; the test-retest reliability of the depression subscale was good (Pearson correlation $=0.78$ ). The depression subscale was dichotomised so that the highest scoring quartile (scores $>3$ ) represented the highest level of depressive symptoms.

\section{Physical functioning}

Physical functioning was assessed at phase 3 and phase 5 by the Short Form 36 General Health Survey (SF-36) and was scored with the MOS scoring system. ${ }^{21}$ The dimension included in this study was physical functioning (Cronbach's $\alpha=0.86$ ). After all items were recoded in the same direction, the scale score was calculated as the sum of the item scores. Subjects whose response was missing for less than $50 \%$ of the items in the scale were assigned an average score based on the items they did respond to. Participants were classified as having poor physical functioning if they were in the lowest quartile of the distribution.

\section{Psychosocial work characteristics}

Work characteristics were primarily measured according to the job strain model, as developed by Karasek and colleagues. ${ }^{22}$ This was measured by self reports of work characteristics in a questionnaire. The work characteristics addressed the main components in the job strain model - that is, decision latitude (Cronbach's $\alpha=0.84$ ), job demands (Cronbach's $\alpha=0.67$ ), and social support (Cronbach's $\alpha=0.79$ ). All scales were divided into tertiles. An alternative model used was the effort-reward imbalance model, as recently developed by Siegrist and colleagues. ${ }^{23}$ The model conceptualises psychosocial stress at work in terms of an imbalance between (extrinsic and intrinsic) efforts and rewards (money, esteem, and status control). High efforts spent in combination with low rewards received, are hypothesised to result in emotional distress and adverse health effects. In a previous Whitehall II analysis, an indicator of effort-reward imbalance was constructed that had three categories: (1) "neither high efforts nor low rewards"; (2) "either high efforts or low rewards", and (3) "both high efforts and low rewards". High efforts were defined by: competitiveness, work related overcommitment, or hostility. Low rewards were defined by: poor promotion prospects or a blocked career. ${ }^{24}$

\section{Social support measures}

Three types of social support (confiding/emotional, practical, and negative aspects of close relationships) were measured from the person nominated as closest on the Close Persons Questionnaire. ${ }^{25}$ This questionnaire measures perceived support received over the past 12 months. By anchoring perceptions of support to a specified time period we aimed to help the respondent focus on actual support received. Measures of social networks were devised from questions about the frequency and number of contacts with relatives, friends, and social groups. ${ }^{26}$ These included a "network beyond the household scale", which captures numbers of contacts beyond the immediate family.

\section{Life events and material problems}

Life events from eight self report questions concerning experiences in the previous 12 months were assessed at phase 1 . Material problems, similar to the concept of major difficulties proposed by Brown and Harris, ${ }^{27}$ were assessed by questions on financial, housing, and neighbourhood difficulties. ${ }^{28}$

\section{Health related behaviours}

Health related behaviours were measured in standard ways: smoking status (never, former, current), and physical activity (greater than one hour vigorous activity per week, less than one hour vigorous activity but greater than one hour moderate activity per week, and less than one hour vigorous or moderate activity per week). Alcohol intake was measured in units and subdivided into categories: none, 1-14 units, 15-21 units, $22+$ units with the highest two categories being combined in women.

\section{Baseline health}

A baseline measure of the GHQ-30 was available but the SF-36 was not included at phase 1. Questions on longstanding illness and overall health status were included. A composite physical illness indicator was constructed that classified people as having a physical illness if they had any one of diabetes, hypertension, ECG abnormalities, or respiratory illness. Blood pressure and body mass index $\left(\mathrm{kg} / \mathrm{m}^{2}\right)$ were measured at the screening examination.

\section{Statistical methods}

Continuous depression scores and physical functioning scores from phase 5 were analysed using linear regression. All analyses were carried out separately for men and women and adjusted for age using five year age bands. Baseline employment grade was used in all analyses. Firstly, we examined the age adjusted association between employment grade and each health outcome. This indicated that there was a linear association between employment grade and both health outcomes. Next, analyses exploring the contribution of potential baseline explanatory factors to grade inequalities were carried out including phase 1 employment grade as a linear term. Then analyses were performed including adjustments for each of the following sets of potential explanatory factors in turn: health behaviours (smoking, alcohol consumption, physical activity); psychosocial work factors (decision latitude, job demands, work social supports, effort-reward imbalance); marital status; social supports (confiding/emotional, practical, negative aspects of close relationships, network size); housing tenure; material problems; and life events. A model was also fitted with an adjustment for baseline health status (physical illness, health problems in past year, depression score, total GHQ score, body mass index, longstanding illness, systolic blood pressure). Finally, the analysis was repeated with simultaneous adjustment for all the above potential explanatory factors. This final model was fitted both with and without adjustment for baseline health status. The percentage reduction in the grade gradient was calculated by comparing regression coefficients for grade before and after adjustment for each explanatory factor or group of factors.

The associations between mental and physical health were investigated using multivariate analysis with depression score 
Table 1 Means, percentage with poor health, and age adjusted odds ratios for depressive symptoms* (GHQ subscale) and SF36 physical functioning t by employment grade

\begin{tabular}{|c|c|c|c|c|c|c|}
\hline & \multicolumn{3}{|l|}{ Depression } & \multicolumn{3}{|c|}{ Physical functioning } \\
\hline & Mean score & Score $>3 \%$ & Odds ratio $(95 \% \mathrm{Cl})$ & Mean score & $\begin{array}{l}\text { Poor functioning } \\
\%\end{array}$ & Odds ratio $(95 \% \mathrm{Cl})$ \\
\hline Men & $(n=4952)$ & & & $(n=5006)$ & & \\
\hline UG1-6 & 0.75 & 9 & 1 & 91.4 & 23 & 1 \\
\hline UG7 & 0.86 & 11 & 1.06 (0.9 to 1.4$)$ & 91.5 & 23 & 1.14 (0.9 to 1.4$)$ \\
\hline SEO & 0.83 & 10 & $0.96(0.7$ to 1.3$)$ & 91.1 & 23 & $1.23(0.9$ to 1.5$)$ \\
\hline HEO & 0.97 & 12 & 1.08 (0.8 to 1.5$)$ & 90.4 & 26 & 1.58 (1.3 to 2.0$)$ \\
\hline $\mathrm{EO}$ & 1.39 & 20 & 2.12 (1.5 to 2.9$)$ & 87.7 & 32 & 2.03 (1.6 to 2.6$)$ \\
\hline Clerical & 1.49 & 22 & $2.44(1.7$ to 3.5$)$ & 83.9 & 37 & 2.31 (1.7 to 3.1$)$ \\
\hline Women & $(n=2089)$ & & & $(n=2119)$ & & \\
\hline UG1-7‡ & 1.01 & 11 & 1 & 87.9 & 16 & 1 \\
\hline SEO/HEO $\ddagger$ & 1.20 & 13 & 1.18 (0.8 to 1.8 ) & 85.0 & 21 & 1.44 (0.9 to 2.1$)$ \\
\hline $\mathrm{EO}$ & 1.33 & 17 & 1.77 (1.1 to 2.8$)$ & 80.3 & 33 & 2.22 (1.5 to 3.2$)$ \\
\hline Clerical & 1.32 & 17 & 1.79 (1.2 to 2.7$)$ & 74.7 & 43 & 3.35 (2.4 to 4.7$)$ \\
\hline
\end{tabular}

*Depressive symptoms defined as scoring $>3$ on depression subscale. †Poor physical functioning defined as being in lowest sex specific quartile. ‡Employment grades UG 1-6; UG7 and SEO/HEO were combined for women because there were smaller proportions of women in these categories.

and physical functioning score as outcomes. ${ }^{29}$ This gave residual correlations between the two outcomes after adjustment for potential explanatory variables. Both depression and physical functioning scores are skewed so analyses were repeated using a log transformation. This had little effect on the pattern of results for grade gradients and only marginally reduced significance levels, so results for grade gradients are presented in terms of raw scores, for ease of interpretation. The residual correlations tended to be lower when using the log transformed scores (indicating that residual correlations for raw scores may be influenced by extreme values on both depression and physical functioning scales) so reported residual correlations are from the log transformed analyses. Analyses of the dichotomised depression and physical functioning measures were carried out using logistic regression.

\section{RESULTS}

Table 1 shows the prevalence of depressive symptoms and poor physical functioning at phase 5 . There is an inverse gradient in both depressive symptoms from the GHQ and in poor physical functioning from the SF-36 General Health Survey by employment grade. Both men and women in the clerical grades have about twice the risk of depressive symptoms and poor physical functioning than men and women in the administrative grades.

Overall, as expected, there was a strong association between depressive symptoms and poor physical functioning in both men and women. This association was little affected by adjustment for employment grade and was apparent within each employment grade with the exception of the top employment grade (table 2). The proportion of men and women with both depressive symptoms and poor physical functioning increased inversely by employment grade. The age adjusted odds ratios for depression given poor physical functioning varied inversely by grade for women. The odds ratios for men also varied inversely by grade with the exception of clerical grade men. The difference in mean depression score for those with poor physical functioning versus those with good functioning again showed an inverse association by employment grade.

The next stage was to assess how much of the grade gradients in phase 5 depressive symptoms and physical functioning were explained by each of the baseline (phase 1) risk factors. In these analyses, grade was included as a linear term and table 3 shows both coefficients for grade gradients in depressive symptom score and physical functioning scores from linear regression

Table 2 Comorbidity within employment grade: percentage with neither, either or both high depression score $(>3)$ and poor physical functioning (low sex specific quartile on SF36 physical functioning scale); age adjusted odds ratio of high depression score by physical functioning; age adjusted difference in mean depression score between those with presence or absence of poor physical functioning

\begin{tabular}{|c|c|c|c|c|c|c|}
\hline & \multicolumn{4}{|l|}{ Percentages } & \multirow[b]{2}{*}{$\begin{array}{l}\text { Odds ratio ( } 95 \% \mathrm{Cl}) \\
\text { of depression given } \\
\text { poor physical } \\
\text { functioning }\end{array}$} & \multirow{2}{*}{$\begin{array}{l}\text { Difference }(95 \% \mathrm{Cl}) \text { in } \\
\text { mean depression score of } \\
\text { those with poor physical } \\
\text { functioning } v \text { the rest of } \\
\text { sample }\end{array}$} \\
\hline & $\begin{array}{l}\text { Neither depression nor } \\
\text { poor physical } \\
\text { functioning }\end{array}$ & Depression & $\begin{array}{l}\text { Poor physical } \\
\text { functioning }\end{array}$ & Both & & \\
\hline \multicolumn{7}{|l|}{ Men } \\
\hline UG1-6 (786) & 70 & 7 & 21 & 2 & $1.04(0.6$ to 1.9$)$ & $0.16(-0.09$ to 0.42$)$ \\
\hline UG7 (1250) & 70 & 7 & 19 & 3 & 2.09 (1.4 to 3.1$)$ & $0.47(0.24$ to 0.70$)$ \\
\hline SEO (919) & 71 & 7 & 19 & 4 & 2.29 (1.4 to 3.6$)$ & $0.50(0.25$ to 0.74$)$ \\
\hline HEO (1086) & 70 & 7 & 21 & 5 & 2.59 (1.7 to 3.8$)$ & $0.60(0.36$ to 0.83$)$ \\
\hline $\mathrm{EO}(575)$ & 57 & 10 & 23 & 9 & 2.69 (1.7 to 4.2 ) & $1.04(0.66$ to 1.41$)$ \\
\hline Clerical (309) & 52 & 11 & 26 & 10 & 1.95 (1.1 to 3.5$)$ & $1.14(0.61$ to 1.67$)$ \\
\hline \multicolumn{7}{|l|}{ Women } \\
\hline UG1-7 (296) & 74 & 9 & 15 & 2 & 0.99 (0.3 to 2.7$)$ & $0.16(-0.39$ to 0.70$)$ \\
\hline SEO/HEO (489) & 69 & 10 & 18 & 3 & 1.44 (0.7 to 2.8$)$ & 0.49 (0.05 to 0.94$)$ \\
\hline EO (424) & 59 & 9 & 24 & 8 & 2.43 (1.4 to 4.1$)$ & $0.85(0.43$ to 1.28$)$ \\
\hline Clerical (857) & 51 & 6 & 32 & 11 & $3.63(2.5$ to 5.4$)$ & $1.17(0.89$ to 1.46$)$ \\
\hline
\end{tabular}


Table 3 Grade gradients in depressive symptoms and physical functioning before and after adjustment for baseline risk factors*

\begin{tabular}{|c|c|c|c|c|}
\hline & \multicolumn{2}{|c|}{$\begin{array}{l}\text { Coefficient for grade gradient ( } \% \text { decline } \\
\text { in grade gradient) } \dagger\end{array}$} & \multicolumn{2}{|c|}{ Odds ratios for grade gradient in poor health } \\
\hline & Depression score & $\begin{array}{l}\text { Physical } \\
\text { functioning }\end{array}$ & Depression score & Physical functioning \\
\hline \multicolumn{5}{|l|}{$\operatorname{Men}(n=4251)$} \\
\hline \multicolumn{5}{|l|}{ Adjustment } \\
\hline Age only & 0.105 & -1.37 & $1.18(1.1$ to 1.3$)$ & $1.18(1.1$ to 1.2$)$ \\
\hline health behaviours & $0.089(15)$ & $-1.18(14)$ & 1.15 & 1.15 \\
\hline work & $0.036(66)$ & $-1.21(12)$ & 1.07 & 1.14 \\
\hline marital status & $0.086(18)$ & $-1.34(2)$ & 1.14 & 1.18 \\
\hline social support & $0.083(21)$ & $-1.29(6)$ & 1.15 & 1.17 \\
\hline housing tenure & $0.096(9)$ & $-1.28(7)$ & 1.17 & 1.17 \\
\hline material problems & $0.079(25)$ & $-1.24(9)$ & 1.14 & 1.16 \\
\hline life events & $0.099(6)$ & $-1.31(4)$ & 1.17 & 1.17 \\
\hline All risk factors & $-0.020(119)$ & $-0.85(38)$ & $0.99(0.9$ to 1.1$)$ & $1.09(1.0$ to 1.2$)$ \\
\hline Baseline health & $0.071(32)$ & $-1.22(11)$ & 1.14 & 1.17 \\
\hline All risk factors + baseline health & $0.013(88)$ & $-0.89(35)$ & $1.03(0.9$ to 1.1$)$ & $1.10(1.0$ to 1.2$)$ \\
\hline \multicolumn{5}{|l|}{ Women $(n=1660)$} \\
\hline \multicolumn{5}{|l|}{ Adjustment } \\
\hline Age only & 0.096 & -2.57 & $1.14(1.0$ to 1.3$)$ & $1.33(1.2$ to 1.4$)$ \\
\hline health behaviours & $0.107(+11)$ & $-2.03(21)$ & 1.15 & 1.27 \\
\hline work & $0.055(43)$ & $-2.71(+5)$ & 1.09 & 1.38 \\
\hline marital status & $0.095(1)$ & -2.55 (1) & 1.14 & 1.33 \\
\hline social support & $0.089(7)$ & $-2.60(+1)$ & 1.13 & 1.35 \\
\hline housing tenure & $0.087(9)$ & $-2.34(9)$ & 1.12 & 1.30 \\
\hline material problems & 0.051 (47) & -2.25 (12) & 1.08 & 1.30 \\
\hline life events & $0.091(5)$ & $-2.47(4)$ & 1.13 & 1.32 \\
\hline All risk factors & $0.033(66)$ & $-1.87(27)$ & 1.05 (0.9 to 1.2$)$ & $1.30(1.2$ to 1.5$)$ \\
\hline Baseline health & $0.074(23)$ & $-2.06(20)$ & 1.11 & 1.31 \\
\hline All risk factors + baseline health & $0.046(52)$ & $-1.66(35)$ & 1.06 (0.9 to 1.2$)$ & $1.31(1.2$ to 1.5$)$ \\
\hline \multicolumn{5}{|c|}{$\begin{array}{l}\text { *Baseline risk factors: health behaviours (smoking, alcohol consumption, physical activity), work (decision latitude, job demands, work social supports, } \\
\text { effort-reward imbalance), marital status, social support (confiding/emotional, practical, negative aspects, network size), housing tenure, material problem } \\
\text { life events in preceding } 12 \text { months, baseline health (physical illness, health problems in past year, depression score, total GHQ score, body mass index, } \\
\text { longstanding illness, systolic blood pressure). †Employment grade included as linear term; percentage change in grade gradient calculated by comparing } \\
\text { regression coefficient after adjustment for each explanatory factor or group of factors with regression coefficient from age adjusted model. }\end{array}$} \\
\hline
\end{tabular}

models and also odds ratios for grade gradients in poor mental and physical health. Results for grade gradients are presented for each group of risk factors in turn and then adjusted for all baseline risk factors.

In men, the grade gradient in depressive symptom score was most attenuated after adjustment for work characteristics (decision latitude, job demands, work social supports, and effort-reward imbalance). Material problems, social supports, marital status, and health behaviours also seemed to explain some of the grade gradient in depressive symptoms scores among men. Both work characteristics and material problems explained some of the grade gradient in depressive symptoms among women. Adjusting for baseline health also led to an attenuation of the grade gradient in depressive symptoms in both men and women. Overall, adjustment for baseline risk factors and baseline health led to an $88 \%$ reduction in the grade gradient in depressive symptoms for men and a 52\% reduction in the grade gradient in depressive symptoms for women. Similar results were obtained from the logistic regression analyses.

With regard to physical functioning, adjustment for health behaviours, work and material problems led to some attenuation of the grade gradient in both men and women, but less so than for depressive symptoms. After adjustment for baseline health and baseline risk factors, the grade gradient in physical functioning score was reduced by $35 \%$ in both men and women.
We next investigated whether these baseline risk factors might also account for some or all of the association between depression and physical functioning. Multivariate analysis, with depression score and physical functioning score as outcomes, was used to obtain the correlation between residuals after adjustment for different sets of risk factors. After adjustment for age, the correlation of residuals was 0.149 for men and 0.175 for women (table 4). These correlations were reduced by about 25\% after adjustment for baseline risk factors with each of these factors explaining a small proportion of the correlation. Adjustment for baseline health alone reduced the correlations by about $20 \%$ and all risk factors together with baseline health reduced the residual correlations by about 33\% (correlation for men: 0.100 , women: $0.110)$.

Similar results for comorbidity were obtained when using binary outcomes. There was still a strong association between poor physical functioning and high depression score after adjustment for employment grade, baseline risk factors and baseline health in both men and women (table 4). Stratified analyses were also carried out to see whether risk factors and baseline health might be having a differential effect on the association between depressive symptoms and physical functioning. Adjusting for age, age and risk factors, age, risk factors, and baseline health tended to reduce the correlation of residuals and odds ratios within each of the employment 
Table 4 Association of depressive symptoms and physical functioning within employment grade before and after adjustment for baseline risk factors* and baseline health status $\dagger$

\begin{tabular}{|c|c|c|c|c|c|c|c|}
\hline \multirow[b]{2}{*}{ Employment grade } & \multicolumn{5}{|c|}{ Odds ratios for high depression score by poor physical functioning $(95 \% \mathrm{Cl})$} & \multicolumn{2}{|c|}{$\begin{array}{l}\text { Residual correlations between } \\
\text { depression and physical } \\
\text { functioning } \neq\end{array}$} \\
\hline & age & age, grade & age, risk factors & $\begin{array}{l}\text { age, baseline } \\
\text { health }\end{array}$ & $\begin{array}{l}\text { age, risk factors } \\
\text { baseline health }\end{array}$ & age & $\begin{array}{l}\text { age, risk factors } \\
\text { baseline health }\end{array}$ \\
\hline \multirow{2}{*}{\multicolumn{8}{|c|}{ Men }} \\
\hline & & & & & & & \\
\hline $1(n=696)$ & 1.17 & & 1.18 & 1.15 & 1.16 & 0.033 & 0.048 \\
\hline $2(n=1107)$ & 2.15 & & 1.98 & 2.01 & 2.10 & 0.144 & 0.103 \\
\hline $3(n=817)$ & 2.37 & & 2.28 & 1.97 & 2.15 & 0.132 & 0.082 \\
\hline $4(n=921)$ & 2.57 & & 2.43 & 2.80 & 3.08 & 0.114 & 0.090 \\
\hline $5(n=469)$ & 2.81 & & 2.19 & 2.23 & 1.91 & 0.211 & 0.120 \\
\hline $6(n=241)$ & 2.09 & & 1.61 & 1.54 & 1.46 & 0.324 & 0.214 \\
\hline All men $(n=4251)$ & $\begin{array}{l}2.29 \\
(1.9 \text { to } 2.8)\end{array}$ & 2.19 & $\begin{array}{l}1.92 \\
(1.6 \text { to } 2.4)\end{array}$ & $\begin{array}{l}2.08 \\
(1.7 \text { to } 2.6)\end{array}$ & $\begin{array}{l}1.97 \\
(1.6 \text { to } 2.5)\end{array}$ & 0.149 & 0.100 \\
\hline \multicolumn{8}{|l|}{ Women } \\
\hline 1 and $2(n=255)$ & 0.89 & & 0.64 & 0.60 & 0.36 & 0.024 & -0.003 \\
\hline 3 and $4(n=422)$ & 1.41 & & 1.18 & 1.33 & 1.32 & 0.105 & 0.057 \\
\hline $5(n=355)$ & 2.94 & & 3.13 & 2.43 & 2.58 & 0.154 & 0.078 \\
\hline $6(n=628)$ & 4.03 & & 3.74 & 4.51 & 4.22 & 0.284 & 0.232 \\
\hline All women $(n=1660)$ & $\begin{array}{l}2.60 \\
(1.9 \text { to } 3.5)\end{array}$ & $\begin{array}{l}2.50 \\
(1.9 \text { to } 3.4)\end{array}$ & $\begin{array}{l}2.34 \\
(1.7 \text { to } 3.2)\end{array}$ & $\begin{array}{l}2.33 \\
(1.6 \text { to } 3.1)\end{array}$ & $\begin{array}{l}2.16 \\
(1.5 \text { to } 3.0)\end{array}$ & 0.175 & 0.110 \\
\hline
\end{tabular}

*Baseline risk factors: health behaviours (smoking, alcohol consumption, physical activity), work (decision latitude, job demands, work social supports, effort-reward imbalance), marital status, social support (confiding/emotional, practical, negative aspects, network size), housing tenure, material problems, life events in preceding 12 months. †Baseline health (physical illness, health problems in past year, longstanding illness, depression score, total GHQ score, body mass index, blood pressure). $¥$ Residual correlations from multivariate analysis of log transformed depression and physical functioning scores.

grades, but only minimally. For women, the odds ratios differed significantly by grade both before and after adjustment for risk factors and baseline health, (significance of interaction after adjustment for risk factors and baseline health $\mathrm{p}=0.001$ ) with greater comorbidity in the lower grades. For men, the pattern was less clear as while the results for the continuous outcomes indicated greater comorbidity in the low grades, this was not the case when analysing as binary outcomes (significance of interaction $\mathrm{p}=0.195$ ).

Table 5 compares the grade gradient in phase 5 depressive symptoms scores in those with and without pre-existing and concurrent physical ill health. For men, there were significant grade gradients in phase 5 depressive symptom scores for both those with and without physical ill health but the grade gradients were consistently stronger in those with physical illness. For women, there were marked differences according to physical health status. Among those women who reported a longstanding illness at phase 1 , there was a significant grade gradient in depressive symptom scores at phase 5 whereas there was no grade gradient in depressive symptom scores among those women who had no longstanding illnesses at baseline. Similar patterns were seen for both phase 3 longstanding illness and poor physical functioning at phases 3 and phase 5 .

\section{DISCUSSION}

Both depressive symptoms and physical functioning demonstrate a gradient by employment grade with higher levels of morbidity in lower levels of employment grades. The proportion of civil servants with both depressive symptoms and physical functioning increased inversely by employment grade. Work characteristics, material problems, and social

\begin{tabular}{|c|c|c|c|c|}
\hline & \multicolumn{2}{|l|}{ Men } & \multicolumn{2}{|l|}{ Women } \\
\hline & \multicolumn{2}{|c|}{ Coefficient (standard error) } & \multicolumn{2}{|c|}{ Coefficent (standard error) } \\
\hline \multicolumn{5}{|c|}{ Longstanding illness at baseline } \\
\hline No & $0.119(0.023)$ & $p=0.023$ & $0.018(0.041)$ & $p=0.67$ \\
\hline Yes & $0.141(0.038)$ & $p<0.001$ & $0.258(0.079)$ & $p=0.001$ \\
\hline \multicolumn{5}{|c|}{ Longstanding illness at S3 } \\
\hline No & $0.108(0.021)$ & $p<0.001$ & $0.044(0.034)$ & $p=0.19$ \\
\hline Yes & $0.150(0.033)$ & $p<0.001$ & $0.217(0.059)$ & $p<0.001$ \\
\hline \multicolumn{5}{|c|}{ Poor physical functioning S3 } \\
\hline No & $0.074(0.019)$ & $p<0.001$ & $0.016(0.030)$ & $p=0.59$ \\
\hline Yes & $0.237(0.045)$ & $p<0.001$ & $0.266(0.087)$ & $p=0.002$ \\
\hline \multicolumn{5}{|c|}{ Poor physical functioning S5 } \\
\hline No & $0.050(0.019)$ & $p=0.008$ & $0.001(0.030)$ & $p=0.99$ \\
\hline Yes & $0.224(0.039)$ & $p<0.001$ & $0.244(0.076)$ & $p=0.001$ \\
\hline \multicolumn{5}{|c|}{ Respiratory illness S5 } \\
\hline No & $0.108(0.018)$ & $p<0.001$ & $0.090(0.031)$ & $p=0.003$ \\
\hline Yes & $0.240(0.070)$ & $p=0.001$ & $0.214(0.141)$ & $p=0.13$ \\
\hline
\end{tabular}


supports explained much of the gradient in depressive symptoms but relatively little of the gradient in physical functioning where health behaviours were a more important explanatory factor. Depressive symptoms and physical functioning were strongly associated within employment grades. However, adjustment for risk factors reduced this association by only $25 \%$, indicating that a common set of risk factors explained only a modest amount of the association of depressive symptoms and physical functioning. Adjustment for baseline health contributed about $20 \%$ of the explanation of the association, and risk factor and baseline health together, about $33 \%$ of the association. Investigation of the gradient in depressive symptoms in women indicated that the employment grade gradient was present in women with longstanding illness or impaired physical functioning but was not present in physically healthy women.

The gradient in depressive symptoms by employment grade is consistent with the gradient in common mental disorder, ${ }^{10}$ major depressive disorder, ${ }^{89}$ and affective disorder. ${ }^{11}$ There tend to be steeper gradients in depressive symptoms than in either anxiety symptoms ${ }^{12}$ or in composite measures of common mental disorder ${ }^{30}$ in this cohort. Additionally, social gradients seem to be shallower with occupationally based measures of social position ${ }^{10}$ than with gradients based on more proximal measures of social disadvantage such as financial strain. ${ }^{31}$ However, employment grade is a precise measure of both income and status and is associated with steep gradients in ill health.

There are a number of limitations to these analyses. The cohort is drawn from a white collar population and thus many aspects of industrial work that might explain the social gradients of physical ill health in those populations have not been accounted for. In addition the coverage of risk factors is not complete: childhood exposures to physical or social deprivation that have been shown to contribute to the explanation of social gradients in adult mental ill health ${ }^{14}{ }^{15}$ are not included in these analyses. Life events are only measured by a brief scale focusing on major events in the previous 12 months so their impact may be underestimated. Depressive symptoms are measured by a brief scale that has not been validated and that is not a measure of clinically recognised psychiatric disorder. Although the symptom scale is reliable it does not indicate the severity or the chronicity of depression. On the other hand physical functioning is measured by a well recognised scale from the SF-36 General Health Survey. Measures of health behaviours at baseline may not adequately account for lifetime health behaviours and our measure of physical activity may be imprecise. Nevertheless, adjusting for smoking history (pack year) and an average of health behaviours on three occasions (phases 1, 2, and 3) made little difference to our results. Nevertheless, these are both self report measures and may be subject to common method bias and negative affectivity that might tend to exaggerate associations. The distinctiveness of the relations between risk factors and depressive symptoms on one hand and physical illness on the other argues that the results cannot be entirely explained by response bias. This paper has one methodological refinement over the earlier paper examining the explanation for gradients in depressive symptoms in this cohort ${ }^{12}$ : the risk factors are prospectively related to depressive symptoms thus reducing the bias associated with cross sectional associations.

Social factors, in particular work characteristics play an influential part in explaining the gradient in depressive symptoms. This has also been shown in cross sectional analyses of this cohort ${ }^{12}$ and in other studies. ${ }^{14}{ }^{15}$ After adjustment for all risk factors the gradient in men is abolished and the gradient in women much reduced. This has implications for interventions ${ }^{9}$ to reduce social inequalities. By addressing social factors there is the potential to greatly reduce social inequalities in depressive symptoms. These results suggest that skill discretion and decision authority or control over work, are an important explanation for the difference in depressive symptoms between employment grades. Previous research, adjusting for employment grade, in this cohort suggests that high levels of psychological demands at work, low social support at work from supervisors and colleagues, and low levels of control at work predict psychological distress over a five year period..$^{32}$ Taken together they suggest that intervention at the level of the workplace rather than the level of the person, may be a suitable public health strategy for improving the mental health of the work force. This has also been suggested in a recent report from the Nuffield foundation. ${ }^{33}$ Of course, not all social factors can be changed easily, and social position and hence work characteristics, that are strongly determined by social position, are not randomly distributed. Nevertheless, it would be defeatist to accept that no positive changes can be made to psychosocial working environments. Patterns of work are currently in flux. Although many current changes in work have negative effects on health some have positive effects: hierarchies have flattened in many organisations, giving workers in lower employment grades more control over work. If the legacy of the 20th century was an improvement in physical working conditions why shouldn't the task of 2 lst century be an improvement in psychosocial working conditions?

It is interesting that the explanations for the grade gradient in physical functioning are different from those for depressive symptoms. As might be expected, health behaviours are generally more important for the gradient in physical functioning, whereas work and material conditions explain very little of the grade gradient.

One possibility is that the strongest predictors of depressive symptoms may not be the same factors that explain the employment grade differences in depressive symptoms. For example, personal social support, in particular low confiding/ emotional support and high negative aspect of close relationships are powerful predictors of psychological distress in this cohort. $^{34}$ Nevertheless, personal social support, perhaps because it does not differ very much between employment grades is not a powerful explanation of grade differences in depressive symptoms. Hence interventions designed to reduce health inequalities might differ from those designed to prevent mental or physical ill health as certain factors may predict differences in morbidity by social position while others, while not differing by social position, nevertheless are risk factors for the morbidity in question. Thus factors that do not relate to inequalities should not be ruled out of preventive interventions, rather they might be expected to act equally across different grades reducing morbidity in each grade but not reducing the gradient in morbidity. Thus, although physical activity may not explain employment grade differences in depressive symptoms, exercise may still be a useful preventive measure for depression.

These analyses do not suggest that common cause is an important explanation of the clustering of mental and physical ill health in the lower employment grades. If there were common causes for mental and physical ill health, there might be interventions that might tackle both types of ill health. On the whole, it would seem that this would only operate for a proportion of the risk factors measured in this study. Interventions to do with work and material conditions could influence gradients in both mental and physical health and thus perhaps these might have special priority. Secondary illness also appeared to be part of the explanation as baseline physical health predicted subsequent depressive symptoms and baseline psychiatric morbidity predicted subsequent physical functioning. In many studies it is known that existing physical ill health is likely to increase vulnerability to subsequent psychological distress or even depressive illness. ${ }^{35}$ Moreover, depressive illness in people with existing coronary heart disease can increase the risk of subsequent mortality. ${ }^{36}$ It seems that it also works in the other direction; that is earlier 
psychological distress may be a predictor of physical illness. Prolonged exposure to psychosocial stressors may lead to psychological distress and in turn to physical illness. Although there is evidence for each step in this pathway there is not good evidence for the whole sequence from psychosocial stressors, through psychological ill health to physical illness.

Could downward social selection by ill health, or lack of promotion because of ill health contribute to these gradients rather than social causation? Previous analyses in this cohort suggest that social selection explained only about $8 \%$ of the gradient in depressive symptoms in men and $27 \%$ in women. ${ }^{8}$

It was unexpected that there was a gradient in depressive symptoms, in women, only among those with existing ill health. Under these circumstances it seems probable that physical ill health preceded the onset of depressive symptoms. It may be that the stressfulness of a longstanding illness is more difficult to cope with in lower employment grades with less access to social and financial resources. Future analyses should address interactions between physical illness, resources and depressive symptoms and employment grade. At baseline (phase 1) there was no overall gradient in depressive symptoms in women. A partial explanation for the emergence of a gradient in depressive symptoms across phase 3 and phase 5 may be attributable to an increasing prevalence of physical illness among women as they age.

\section{ACKNOWLEDGEMENTS}

We thank all participating civil service departments and their welfare, personnel and establishment officers; the Occupational Health and Safety Agency; the Council of Civil Service Unions; all participating civil servants in the Whitehall II study; and all members of the Whitehall II study team. The work presented in this paper was supported by a grant from the Economic \& Social Research Council (L128251052). The Whitehall II Study is supported by grants from the Medical Research Council, Health and Safety Executive, Department of Health, British Heart Foundation, National Heart Lung and Blood Institute (2 ROI HL36310), National Institute on Aging (AG13196), Agency for Health Care Policy Research (5 RO1 HS06516), the New England Medical Center-Division of Health Improvement, Institute for Work and Health and the John D and Catherine T MacArthur Foundation Research Networks on Successful Midlife Development and Socioeconomic Status and Health.

\section{Authors' affiliations}

S A Stansfeld, J Head, V Cattell, Department of Psychiatry, Institute of Community Health Sciences, Barts and the London, Queen Mary's School of Medicine and Dentistry, Queen Mary, University of London, UK J Head, J Wardle, Department of Epidemiology and Public Health, University College, London, UK

R Fuhrer, Joint Departments of Epidemiology and Biostatistics and Occupational Health, McGill University, Montreal, Canada

\section{REFERENCES}

1 Marmot MG, Shipley M, Rose G. Inequalities in death-specific explanations of a general pattern. Lancet 1984;i:1003-6.

2 Marmot MG, Davey Smith G, Stansfeld S, et al. Health inequalities among British civil servants: the Whitehall II study. Lancet 1991;337:138-93

3 Eachus J, Williams M, Chan P, et al. Deprivation and cause-specific morbidity: evidence from the Somerset and Avon Survey of Health. BM 1996; 31 2:287-92.

4 Mackenbach JP, Cavelaars AE, Kunst $A E$, et al. Socioeconomic inequalities in cardiovascular disease mortality; an international study. Eur Heart J 2000;21:1141-51.
5 Mackenbach JP, Kunst AE, Groenhof $F$, et al. Socioeconomic inequalities in mortality among women and among men: an international study. Am J Public Health 1999;89:1800-6.

6 Cardano M, Costa G, Demaria M, et al. Inequalities in mortality in the Italian longitudinal studies. Epidemiol Prev 1999;23:141-52.

7 Krokstad S, Kunst AE, Westin S. Trends in health inequalities by educational level in a Norwegian total population study. J Epidemio Community Health 2002;56:375-80.

8 Dohrenwend BP, Levav I, Shrout PE, et al. Socioeconomic status and psychiatric disorders: the causation-selection issue Science 1992;225:946-52.

9 Kessler RC, McGonagle KA, Zhao S, et al. Lifetime and 12-month prevalence of DSM-III-R psychiatric disorders in the United States. Arch Gen Psychiatry 1994;51:8-19.

10 Lewis G, Bebbington P, Brugha T, et al. Socioeconomic status, standard of living, and neurotic disorder. Lancet 1998; 352:605-9.

11 Muntaner C, Eaton WW, Diala C, et al. Social class, assets, organizational control and the prevalence of common groups of psychiatric disorders. Soc Sci Med 1998:47:2043-53.

12 Stansfeld SA, Head J, Marmot MG. Explaining social class differences in depression and well-being. Soc Psychiatry Epidemiol 1998;33:1-9.

13 Marmot $M$, Bosma H, Hemingway $\mathrm{H}$, et al. Contribution of job contro and other risk factors to social variations in the coronary heart disease incidence, Lancet 1997:350:235-9.

14 Power C, Manor O. Explaining social class differences in psychological health among young adults: a longitudinal perspective. Soc Psychiatry Epidemiol 1992;27:284-91.

15 Lundberg $\mathbf{O}$. Causal explanations for class inequality in health-an empirical analysis. Soc Sci Med 1991;32:285-393.

16 Eastwood MR, Trevelyan MH. Relationship between physical and psychiatric disorder. Psychol Med 1980;2:363-72.

17 Stansfeld SA, Davey Smith G, Marmot M. Association between physical and psychological morbidity in Whitehall II Study. J Psychosom Res 1992:37: 1-12.

18 Najman JM. Theories of disease causation and the concept of general susceptibility: a review. Soc Sci Med 1980;14A:231-7.

19 Goldberg DP. The detection of psychiatric illness by questionnaire. Oxford: Oxford University Press, 1972

20 Goldberg DP, Hillier V. A scaled version of the General Health Questionnaire. Psychol Med 1978;9:139-45

21 Ware JE, Sherbourne CD. The MOS short-form Health Survey (SF-36): I. Conceptual framework and item selection. Med Care 1992;30:473-83.

22 Karasek R, Theorell T. Healthy work: stress, productivity, and the reconstruction of working life. New York: Basic Books, 1990.

23 Siegrist J. Adverse health effects of high-effort/low-reward conditions. J Occup Health Psychol 1996;1:27-41.

24 Bosma H, Peter R, Siegrist J, et al.. Two alternative job stress models and the risk of coronary heart disease. Am J Public Health 1998;88:68-74.

25 Stansfeld SA, Marmot MG. Deriving a survey measure of social support the reliability and validity of the close persons questionnaire. Soc Sci Med 1992;35:1027-35.

26 Berkman LF, Syme SL. Social networks, host resistance, and mortality: a nine year follow-up study of Alameda County residents. Am J Epidemiol 1979;109:186-204.

27 Brown GW, Harris T. Social origins of depression: a study of psychiatric disorder in women. London: Tavistock, 1978.

28 Pearlin LI, Schooler C. The structure of coping. J Health Soc Behav 1978;19:2-21.

29 Goldstein H. Multilevel statistical models, London: Edward Arnold, 1995.

30 Stansfeld SA, Marmot MG. Social class and minor psychiatric disorder in British civil servants: a validated screening survey using the general health questionnaire. Psychol Med 1992;22:739-49.

31 Weich S, Lewis G. Poverty, unemployment, and the common mental disorders: population based cohort study. BM 1998;317:115-19.

32 Stansfeld SA, Fuhrer R, Shipley M, et al. Work characteristics predict psychiatric disorder: prospective results from the Whitehall II Study. Occup Environ Med 1999;48:302-7.

33 Williams S, Michie S, Patani S. Improving the health of the NHS workforce: report of the partnership on the health of the NHS workforce. London: Nuffield Trust, 1998.

34 Stansfeld SA, Fuhrer R, Shipley M. Types of social support as predictors of psychiatric disorder in a cohort of British Civil Servants (Whitehall II Study). Psychol Med 1998;28:881-92.

35 Schleifer SJ, Macari-Hinson MM, Coyle DA, et al.The nature and course of depression following myocardial infarction. Arch Intern Med 1989;149:1785-9.

36 Frasure-Smith $\mathbf{N}$, Lesperance $F$, Talajic M. Depression following myocardial infarction. Impact on 6 month survival. JAMA 1993;270:1819-25. 